\title{
RODOLFO MONDOLFO \\ E O INÍCIO DA FILOSOFIA GREGA
}

\author{
Regina Célia Bicalho PRATES E SILVA*
}

RESUMO: O presente artigo pretende chamar a atenção para o papel representado por Rodolfo Mondolfo, com sua teoria da dependência da primeira filosofia grega em relação a uma reflexão anterior sobre o homem e a vida social, na "viragem" que reinseriu na história o início da filosofia.

UNITERMOS: Filosofia; história da filosofia; filosofia e mito; filosofia e cultura; filosofia e vida social; filosofia e política.

Foi em seu famoso artigo intitulado “Do mito à Razão”, de 1957 (22) que J.P. Vernant expôs o essencial de suas idéias sobre o início da filosofia grega. Desenvolveu-as, mais tarde, no livro "As Origens do Pensamento Grego"' (21). Em ambos os textos, ele se insurge contra certa corrente de historiadores de Filosofia, segundo pensa bem representada por $\mathrm{J}$. Burnet, que dá a ela um papel de "viajante sem bagagem"': começo absoluto, fruto de uma descontinuidade radical na história (22:294). Só com a obra de R.G. Cornford parece-lhe ocorrer "uma viragem na maneira de abordar o problema das origens da filosofia e do pensamento racional'" (22:298), e por isso Vernant toma-a como ponto de partida de suas próprias investigações.

A preocupação fundamental de Cornford foi "restabelecer, entre a reflexão filosófica e o pensamento religioso, que a tinha precedido, o fio da continuidade histórica"' (22:298). Em “From Religion to Philosophy", de 1912, ele tenta, pela primeira vez, estabelecer o liame entre o pensamento religioso e os começos do conhecimento racional; mas só em "Principium Sapientiae", publicado em 1952, alguns anos após a morte do autor, fica estabelecida em definitivo a origem mítica e ritual da primeira filosofia grega. Segundo Vernant, Cornford mostra que a "física" jônica nada tem em comum com a ciência que designamos com esse nome, já que ignora a observação direta da natureza e a experimentação; trata-se apenas de uma transposição, "numa forma laicizada e em um plano de pensamento mais abstrato", do sistema de representações elaborado pelo mito (22:295). As cosmologias dos filósofos retomam e prolongam os mitos cosmogônicos, uma vez que procuram resposta para o mesmo tipo de pergunta ("como pode emergir do caos um mundo ordenado?' ') e utilizam um material conceitual análogo. Nessas circunstâncias, a filosofia representa a racionalização do mito (22:298).

Entretanto, e sem que isso implique, de modo algum, em desvalorização do trabalho de Cornford, é preciso reconhecer que, ao contrário do que afirma Vernant, ele não foi o único responsável pela "viragem" que reinseriu a filosofia na história. Seria possível rastrear toda uma "família teórica" que levantou sugestões nesse sentido. Entretanto, o que pretendo, neste momento, é mostrar que Rodolfo Mondolfo, em datas muito anteriores,

* Professora Assistente-Doutora do Departamento de Ciências Sociais e Filosofia - Instituto de Letras, Ciências Sociais e Educação - UNESP - 14800 - Araraquara - SP - Brasil. 
à da publicação do último livro de Cornford, chamou repetidamente a atenção para a relação existente entre a primeira filosofia grega e outras manifestações culturais, inclusive o pensamento religioso*. É verdade que a preocupação fundamental de Mondolfo em seus estudos sobre o início da filosofia grega era corrigir o "erro histórico" representado pela afirmação de que a meditação filosófica começa na Grécia tendo por objeto a natureza (ver 4 e 9), enquanto a de Cornford, como vimos, situa-se no esclarecimento das relações entre mito e filosofia; no que concerne, porém, ao ponto fundamental, que é a articulação da filosofia com o contexto histórico, impedindo, de modo categórico, qualquer veleidade de referência a um "milagre",**, é preciso reconhecer que a contribuição de Mondolfo é tão importante quanto a de Cornford. De qualquer modo, o trabalho de ambos leva necessariamente a uma transformação no modo de encarar o início da filosofia grega.

Mas examinemos um pouco mais de perto as idéias de Mondolfo. "Os documentos e as notícias que temos sobre uma atividade intelectual anterior ao surgimento das primeiras escolas filosóficas demonstram um vivo fermento de pensamento, que ia preparando o desenvolvimento da Filosofia'" $(3: 15)^{* * *}$. O naturalismo dos primeiros filósofos não representa, pois, o processo inicial da reflexão grega, mas, ao contrário, o pensamento grego só pôde atingi-lo com base em uma reflexão anterior. Essa reflexão anterior é representada, de um lado, pelas teogonias, primeiras tentativas de explicação da natureza em seu conjunto, situadas ainda inteiramente no terreno do mito; e, de outro, pela obra dos poetas gnômicos e o trabalho dos chamados "Sete Sábios" (3:17). Ela se exprime, pois, em forma poética, e se não pode ser considerada filosofia em sentido próprio, não deve ser deixada de lado quando o que nos propomos é descobrir as vinculações históricas da filosofia.

As teogonias míticas gregas adiantaram-se à filosofia na tentativa de esclarecer as relações percebidas entre os fatos naturais. Os próprios representantes da concepção tradicional sobre o início da filosofia reconheceram que a meditação filosófica tivera "um antecedente" nas representações religiosas, que apresentavam, em forma mítica, "os mesmos problemas que mais tarde a filosofia em forma racional levantou' (10:17-18). Mas uma das idéias básicas de Mondolfo é justamente a de que a característica essencial de toda teogonia (e não apenas da grega) é que "seu caráter mítico está determinado pelo fato de que se extraem do mundo humano, das experiências da vida e das relações sociais, da geração e da luta, os elementos fundamentais para as suas explicações e interpretações do devir cósmico, e é por isso que representam as relações entre os seres e as forças, os fenômenos e momentos do imenso processo universal como relações entre personalidades concebidas antropomorficamente, , (10:3435). Por isso, também nas teogonias gregas (na de Hesíodo, por exemplo) os problemas cósmicos "são concebidos essencialmente como problemas humanos, modelados sobre o exemplo dos mes-

*Cito, aqui, apenas como exemplo, alguns trabalhos em que Mondolfo abordou a questão; ver, por ordem cronológica, 16,15,9,11,2,8,6,14,7,17,4. Para a bibliografia completa de Mondolfo, consultar 18. Notar que em 10: 9-41, Mondolfo chama a atenção para o fato de que o parentesco existente entre a filosofia naturalista e a poesia teogonica (ou, em outras palavras, entre o pensamento filosófico e o pensamento religioso) já havia sido assinalado por Platão (principalmente no Sofista, 242c, e no Fedão, 96a) e por Aristóteles (Metafísica, I,2, 982e e I, 4, 984) e para o reconhecimento desse fato por Heidel, em 1910 (ver 1). $(22: 294)$

**" Tal é o sentido do "milagre grego": através dos jônios, reconhece-se a Razão intemporal encarnada no tempo"

***A tradução desta, como das outras citações de Mondolfo, é minha. 
mos" (9:18), com a personificação dos elementos naturais e a concepção de suas relações "como se estivessem governados pelas mesmas forças que regem as relações entre os homens" (3:16). O que supõe, evidentemente, que "ao contemplar e tentar compreender a natureza, o pensamento mítico já possui os conceitos relativos ao mundo humano"' e por isso mesmo pode empregá-ios (10:18), dando aos deuses (particularmente aos mais importantes entre eles) "caracteres e relações recíprocas análogos aos que of erecem os homens e a sociedade humana" (10:18). Assim, as teogonias míticas estão longe de representar o ponto de partida da reflexão grega, pois na Grécia como em todos os outros lugares, "a reflexão sobre o mundo humano precedeu a reflexão sobre o mundo natural e por isso esta pode apoiar-se sobre aquela, quando surge pela primeira vez' (10:18).

Quando a filosofia da natureza aparece, ela conserva algumas das características fundamentais das teogonias: coloca os mesmos problemas (antes de mais nada, o problema "das fontes e do termo de todas as coisas" (10:34) e mantém a "vestidura mística", isto é, a dependência em relação a uma reflexão prévia sobre o mundo humano (10:19). Assim, nas primeiras cosmologias filosóficas reconhecemos a mesma projeção, na natureza, das tendências e potências reveladas pela experiência social na esfera humana, que já encontráramos na mitologia antropomórfica (10:22-23): ao recolher a herança de reflexão das teogonias, a filosofia incipiente herdou também uma concepção da natureza dependente de uma consideração anterior do mundo humano (10:23)*.

As relações existentes entre o naturalismo filosófico e uma primeira forma de poesia, a teogonia mítica, acabam sendo, pois, bem mais complexas do que se pode- ria pensar a princípio; a aproximação existe não apenas em relação ao tema fundamental de reflexão (como se percebe imediatamente), mas também em relação ao aparato conceitual, resultante, num caso como no outro (ou melhor, num caso porque no outro) de uma reflexão sobre o homem, sua vida e seu mundo muito antiga, talvez mesmo "tão antiga quanto a humanidade pensante" (3:15). Mondolfo pode, então, afirmar, que "em suas concepções de gênese e da constituição do cosmo, tanto as teogonias poéticas quanto as cosmogonias filosóficas gregas partem das concepções e representações referentes às relações entre os homens e suas gerações"' (5:151).

Por outro lado, na opinião de Mondolfo, o antropomorfismo das teogonias não seria, por si só, suporte suficiente para os temas e esquemas de pensamento das primeiras cosmologias filosóficas; o naturalismo filosófico acrescentou, à inspiração vinda dessa reflexão sobre o homem, muito geral e antiga, uma outra, proveniente de um novo tipo de reflexão, bem mais próximo: a dos poetas gnômicos e dos "Sábios", preocupados com a vida humana nos quadros da nova forma de vida social que se estabelecera na Grécia, a "pólis". De modo que, para ele, as raízes da primeira filosofia firmam-se, ao mesmo tempo, em dois tipos de reflexão sobre o homem: aquela que lhe chegou através da teogonia e a dos poetas e sábios da Grécia arcaica, preocupados fundamentalmente com os problemas éticos, religiosos e sociais da "pólis". "O filósofo naturalista não teria chegado à sua teoria metafísica se o poeta moralista não lhe tivesse of erecido sua sugestão, por meio da reflexão sobre os problemas humanos" (5:152). A reflexão sobre o homem e a vida no interior da "pólis", realizada pelos poetas e que resultou em conceitos como

* "Das teogonias em diante, as idéias necessárias para a interpretaçào dos processos cósmicos sâo extraídas da experiência da vida humana; e o hábito mental formado e manifestado nas teogonias repercute, mais tarde, nas cosmologias filosóficas"'(10:36). 
PRATES E SILVA, R.C.B. - Rodolfo Mondolfo e o início da filosofia grega. Trans/Form/Ação, São Paulo, 4:51-60, 1981.

"lei", “justiça", “cosmos", "poder", "luta", etc. * deve ser considerada antecedente tão ou mais importante, para o naturalismo dos primeiros filósofos, do que as teognonias míticas, único antecedente apontado por Cornford. O conceito de "lei" foi particularmente importante: constituiu um instrumento de ordenamento e sistematização sem o qual a reflexão filosófica sobre a natureza não teria sido possível (10:36 e segs.); mas todos os outros citados tiveram um papel fundamental, diretivo, de tal modo que Mondolfo chega a afirmar que "os poetas gnômicos e moralistas e os chamados 'Sete Sábios' são os precursores e preparadores da reflexão filosófica e têm que ser inseridos na cadeia de seu desenvolvimento histórico como elo anterior e necessário, sem o qual o elo sucessivo permanece suspenso no vazio e não se pode compreender em sua verdadeira realidade e em seu genuíno significado histórico $(5: 152)$. Ou, indo ainda mais longe, que "toda visão unitária da natureza não é senão uma projeção, no universo, da visão da 'pólis' $(3: 17)^{* *}$ querendo dizer, é claro, que por ter um caráter mais sistemático e por estar mais próxima, no tempo, do início da filosofia, essa nova reflexão sobre o mundo humano pesou muito mais do que a que lhe viera, por assim dizer, em segunda mão, através das teogonias.

Não se deve, também, esquecer que essa reflexão interior à "pólis" foi parte de uma transformação muito mais geral, que atingiu vários aspectos da vida e da cultura. Por isso, apesar de acentuar as relações existentes entre a filosofia nas- cente e a reflexão desenvolvida através da poesia, Mondolfo não deixa de mencionar outros relacionamentos do naturalismo pré-socrático: com as novas formas religiosas que então se manifestam, com os progressos das técnicas artesanais e com os conhecimentos adquiridos no contato com as grandes civilizações orientais, então reativados. "A vinculação do naturalismo pré-socrático com as concepções relativas ao homem se nos apresenta a uma luz mais completa e viva ao considerá-la em outro aspecto, constituído por sua conexão com a história das idéias religiosas... Não se deve esquecer ou descuidar da importância que tem no desenvolvimento do naturalismo filosófico, outro fator, constituído por uma transformação prof unda das idéias religiosas, que significa uma transformação radical do conceito de homem"' (5:154-155). "Com as sugestões dos moralistas colaboram, no naturalismo pré-socrático, muitas outras, procedentes das técnicas dos artesãos e utilizadas para a compreensão dos processos naturais"' (13:100). "A prioridade da reflexão sobre o mundo humano em relação à que se dirige ao mundo natural aparece confirmada ainda em outro aspecto. As concepções dos processos cósmicos e as explicações de sua geração propostas pelos naturalistas pré-socráticos são tomadas... de sugestões of erecidas pelas técnicas criadas pelos homens e utilizadas na época daqueles naturalistas"' $(5: 153)^{* * *}$.

De qualquer modo, as idéias fundamentais de Mondolfo são que a primeira reflexão sobre a natureza, tanto em sua forma mítica como em sua forma filosófi-

* "Não só as cosmogonias filosóficas modelam-se em parte sobre precedentes teogonias míticas, dominadas pelas relaçðes de geração e de luta, mas o próprio conceito de 'cosmos' é tomado do mundo humano... para ser aplicado à natureza e a idéia de lei natural apresenta-se, a princípio, como idéia de justiça" (3:17). "Esse naturalismo conserva elementos e caracteres que revelam sua divida para com o humanismo anterior dos gnômicos e dos poetas moralistas, de cujas reflexðes, formadoras dos conceitos de lei, justiça, ordem, amor, luta, etc. tira as idéias inspiradoras e organizadoras de sua visão do cosmos e as explicaçðes dos processos que se desenvolvem nele"' (13:100).

** Ou "a própria idéia de cosmos, de sua ordem e de suas leis não é, a princípio, nada mais do que a projeção da pólis no mundo natural" (5:151).

***Em relação à importância do contato com os conhecimentos das grandes culturas orientais, ver principalmente a "Introdução" de 3 e a "Nota sui rapporti fra la cultura e speculazione orientale e la filosofia e la scienza greca", em 7 . Ver também 5:156. 
ca, se enlaça sempre com uma reflexão sobre o mundo humano, que a precede e em que se apóia, buscando quadros e conceitos diretivos *; e que o naturalismo filosófico, além de receber, através das teogonias míticas, o resultado de uma reflexão muito antiga e difusa, teve também a seu dispor uma reflexão mais recente e caracteristicamente grega (porque realizada nos quadros da "pólis" e tendo por finalidade organizar do melhor modo possível a vida humana nesse contexto), a dos poetas preocupados com a moral e a política. Nesse sentido, é possível e legítimo aplicar a teoria de Mondolfo sobre o início da filosofia (a dependência em relação à reflexão sobre o mundo humano) a frase usada por Vernant para caracterizar o pensamento de Cornford sobre a dependência da filosofia em relação à mitologia: "Os filósofos não precisaram inventar um sistema de explicação do mundo: acharamno já pronto"' (22:298).

Ora, se por sua argumentação a favor do relacionamento da filosofia com formas anteriores de reflexão, expressas de modo poético, Mondolfo torna-se participante, ao lado de Cornford, na obra de reinserção da filosofia na história, ele se aproxima muito do próprio J.P. Vernant ao ressaltar a dependência da investigação da natureza em relação à investigação do mundo humano.

Com efeito, Vernant não aceita passivamente as afirmações de Cornford. Considerando que, graças à sua obra, a filiação da filosofia em relação ao mito foi firmemente estabelecida, mas que "através de sua demonstação se tem, por vezes, o sentimento de que os filósofos se contentam em repetir, em uma linguagem diferente, o que já dissera o mito (22:298),
Vernant preocupa-se em deslindar as condições históricas específicas que permitiram, na Grécia do século VI A.C., o aparecimento da "mutação mental" ** que tornou possível a filosofia. Nesse momento, deixando Cornford de ser um guia útil, ele se volta para o Essai sur la Formation de la Pensée Grecque, de Pierre Maxime Schuhl, publicado em 1949 (19), e para o discutido livro de G. Thomson, The First Philosophers, de 1955 (20).

Estudando as transformações sociais e políticas ocorridas na Grécia, no período arcaico, Schuhl acentua a função libertadora que tiveram, para o espírito, instituições como a moeda, o calendário, a escrita alfabética; e afirma que práticas como a navegação de longo curso e a expansão do comércio deveriam causar "uma nova orientação do pensamento'” (19:151 175). Thomson, por sua vez, insiste na importância de dois grupos de fatos do mesmo período histórico: a ausência, na Grécia, de uma monarquia de tipo oriental e o início de uma economia mercantil, com o conseqüente aparecimento de uma classe de comerciantes para a qual os objetos tendem a despojar-se de sua diversidade qualitativa (20). Vernant é de parecer que todos esses aspectos têm como denominador comum o aparecimento da "pólis". Por isso, em seu As Origens do Pensamento Grego, ele desenvolve a idéia, lançada no último parágrafo do artigo "Do Mito à Razão", de que "a filosofia é filha da cidade"' (22:319).

Fica claro, nessa obra, que aquilo em que a Grécia se reconhece, que define aos seus próprios olhos sua originalidade, é ao mesmo tempo uma forma de vida social e um certo tipo de reflexão $(21: 6)$. A derrota da realeza miceniana, com o ad-

*"A primeira reflexão sobre a natureza se enlaça sempre, pois, com a reflexão sobre o mundo humano, que deve havê-la precedido para poder dar-lhe seus próprios quadros e conceitos diretivos" (3:17). "Os conceitos diretivos e sistemáticos das primeiras concepçðes naturalistas tendo sido tomados do mundo humano e social, demonstram, com plena evidência, que o problema da natureza está associado aos relativos à vida e às criaçð̄es do homem e da sociedade'" (3:35). Ver também 10:151 e 13:100.

**Conceito básico em Vernant. 
vento da "pólis", ultrapassa o domínio da história política e social; repercute no próprio homem grego, modificando seu universo espiritual; de fato, "é no plano político que a Razão, na Grécia, primeiramente se exprimiu, constituiu-se e formou-se'" (21:94). A originalidade da filosofia em relação ao mito é conseqüência direta da "laicização do pensamento" tornada possível pelo novo tipo de organização da vida humana, no interior da “pólis"' (21:7). Na verdade, a primeira sabedoria grega, característica dos homens que os gregos celebraram sempre como seus primeiros e mais autênticos sábios, e que marca o momento de ruptura com a explicação mítica do real, "não tem por objeto o universo da 'physis', mas o mundo dos homens: que elementos o compõem, que forças o dividem contra si mesmo, como harmonizá-las, unificá-las, para que de seus conflitos surja a ordem humana da cidade" (21:27). "O declínio do mito" data do dia em que "os primeiros sábios puseram em discussão a ordem humana" (21:94). Ao nascer, a filosofia se enraíza profundamente nesse novo pensamento político, traduzindo suas preocupações fundamentais e tirando dele parte de seu vocabulário (21:95). À mudança de registro e à utilização de um vocabulário profano, operadas pela filosofia nascente, correspondem, pois, uma nova atitude de espírito, um novo clima intelectual, diretamente relacionado com a racionalização da vida social na "pólis"' $(21: 76)$. À investigação da natureza feita pelos milesianos projeta sobre o mundo físico a concepção da lei e da ordem que, triunfante na cidade, fez do mundo humano um "cosmos" (21:76-77). A grande "viragem" deu-se, portanto, quando os primeiros sábios começaram a refletir sobre a vida humana tal como se apresenta na "pólis"; os filósofos aproveitaram o espaço assim aberto para a reflexão e voltaram-se para a natu- reza. Assim, do mesmo modo que pudemos aplicar ao pensamento de Mondolfo uma frase de Vernant, podemos agora caracterizar o pensamento de Vernant através de uma afirmação que já encontramos em Mondolfo: " toda visão unitária da natureza não é senão uma projeção no universo da visão da "pólis" (3:17 e 5:151).

Mas a coincidência entre os dois estudiosos não aparece apenas nesse aspecto geral e fundamental de afirmar a dependência da reflexão filosófica em relação à reflexão sobre o mundo humano (especialmente em relação ao primeiro pensamento "político" grego); surge, também, em aspectos mais particulares.

Um exemplo. Já vimos que, para não correr o risco de parecer afirmar, com Cornford, que os filósof os "se contentam em repetir, em linguagem diferente, o que já dissera o mito", Vernant se aplica em pôr em relevo a originalidade da filosofia: "já não se trata apenas de encontrar na filosofia o antigo, mas de destacar o verdadeiramente novo, aquilo que faz precisamente com que a filosofia deixe de ser mito para se tornar filosofia" (22:298)*. Essa é a preocupação que norteia As Origens do Pensamento Grego.

Mondolfo, por sua vez, na famosa "Nota sopra la religione greca i suoi rapporti con la filosofia" (7:140 e segs.), também se recusa a aceitar a tese de Cornford porque, no seu entender, ela isola uma "realidade histórica complexa", como é a formação e o desenvolvimento da filosofia natural grega, da multiplicidade de fatores que para ela concorrem: retendo apenas alguns desses elementos - e justamente os que podem ser considerados "sobrevivências" e "resíduos" - ela transforma um grupo particular de elementos preparatórios em "primeira forma' (7:157). A descoberta das possibilidades e germes presentes em uma reflexão

*"A filosofia, se traduz aspiraçðes gerais, coloca problemas que só a ela pertencem" (22:318). "apesar dessas analogias e reminiscências, não há realmente continuidade entre o mito e a filosofia”" (21:76). 
anterior - religiosa, moral e política que serviram de matéria e estímulo para a filosofia naturalista não pode levar-nos a reduzir a importância do aparecimento da filosofia, que opera "pela primeira vez na história espiritual da humanidade a decisiva passagem da reflexão e das concepções da realidade universal do mito à ciência" (7:165).

Outro ponto de contato importante é que, embora sejam ambos firmes partidários da historicidade da filosofia e de sua relação com a reflexão política anterior, nem Vernant nem Mondolfo pretendem transformá-la em mero "reflexo" dessas condições exteriores. Vernant formula esse pensamento explicitamente mais de uma vez *, e talvez seja esse o motivo pelo qual, embora considere a filosofia "filha da cidade", ao desenvolver considerações sobre problemas específicos, ele empregue expressões menos fortes, para designar as relações entre o pensamento filosófico e a "pólis": solidariedade, parentesco, analogia, etc. (Ver 23 e 24). Mondolfo, por sua vez, embora insista na idéia de que a reflexão começou na Grécia tomando por objeto não o mundo da natureza, mas o mundo humano, e afirme constantemente as vinculações da Filosofia com outras manifestações culturais, evita pensá-la como puro jogo mecânico de forças estranhas a ela (5:148-150). Pelo contrário, ele se preocupa em salientar o "contínuo intercâmbio" existente entre a filosofia e outros aspectos da vida espiritual grega (5:157-158) e afirma que a compreensão do processo histórico ocorrido exige o reconhecimento de sua natureza dialética (5:148 e 7:165-166).

Existe, porém, entre os dois helenistas, uma diferença fundamental: enquanto Vernant não é um especialista em História da Filosofia e chega à questão da hisioricidade da filosofia através da des- coberta de uma "razão grega" relacionada com o mito e a "pólis" - isto é, enquanto sua atenção, ao dirigir-se para a filosofia, focaliza-se no início da filosofia grega - Mondolfo considera suas investigações sobre a primeira filosofia grega apenas uma parte de uma História da Filosofia que não se limita a acompanhar "o desenvolvimento progressivo do pensamento filosófico", mas se constitui num aspecto especial de uma história geral da cultura (5:145). Essa diferença é importante, porque decorre de quadros teóricos que, embora possam talvez ser considerados da mesma "família", absolutamente não se sobrepõem. Mondolfo declara-se tributário de Hegel e do historicismo do século XIX (5:149 e 13:98): seu objetivo primordial de desenvolver uma história da filosofia que não se limite a compreender e construir uma "Dialética interna", mas seja capaz de colocar a filosofia no seio de uma história da cultura, totalizante tanto no sentido das histórias nacionais (a da Grécia, por exemplo), como no da história geral da humanidade (5:148-149), encontra respaldo no conceito de "Espírito objetivo", no seu entender perfeitamente apto a dar conta, ao mesmo tempo, da "multiplicidade de exteriorizações" e da "unidade profunda" das manifestações culturais $(5: 146)$. É a partir desse quadro teórico que Mondolfo, de um lado, não se contenta em estabelecer as relações da filosofia incipiente apenas com as teogonias míticas e a reflexão "política" (como faz Vernant), mas acha necessário referi-la, também, ao desenvolvimento das letras e das artes, à história das instituições, dos costumes, da economia, do direito, das técnicas, das religiões, etc; e, de outro, que ele julga que essas vinculações iniciais da filosofia grega não são um caso isolado, mas fornecem-nos a chave para compreender qualquer filosofia, em qualquer tempo.

*Por exemplo em 22:315 e 318. Ver também 29:180-182. 
A filiação teórica de Vernant é diversa e expressa de modo menos claro. $\mathrm{Na}$ "Introdução", de Mito e Pensamento entre os Gregos (26), de 1965, ele se apresenta como alguém que se esforça por aplicar ao domínio dos "estudos gregos" a "psicologia histórica" de I. Meyerson*; mas na "Introdução" de Mythe et Société en Grèce Ancienne (27), de 1974, referindose ao anterior Mito e Tragédia na Grécia antiga (escrito em colaboração com $\mathrm{P}$. Vidal-Naquet) (28), fala em uma "dupla orientação metodológica": análise estrutural dos textos, "para descobrir neles sistemas de pensamento"' e pesquisa histórica, "única capaz de explicar as transformações, as inovações, os remanejamentos estruturais no seio de um sistema"' (27:8). Além disso, tem-se a impressão de que Vernant usa o conceito de história em um sentido muito amplo, podendo voltar-se tanto para a interpretação marxista** quanto para uma "história suciologizante', na linha de Louis Genet; não rejeita, também, contribuições vindas da sociologia propriamente dita, da psicologia e da antropologia (28:9 e 29). De qualquer modo, mesmo quando ele deixa o nível da pura análise estrutural do texto, as preocupações de Vernant localizam-se em momentos de ruptura; assim a filosofia jônica constitui-se a partir de um profundo corte na história da Grécia, o que foi produzido pela consolidação da "pólis" (21:5-7); e a tragédia aparece quando a cidade democrática rompe com suas tradições de tal modo que "a linguagem do mito deixa de apreender a realidade política da cidade'" (28:7). Isso certamente ainda tem algo a ver com o estruturalismo e implica em uma investigação mais apta a dar conta da emergência do novo do que a produzir uma visão ampla da continuida- de. Enfim, Vernant privilegia, confessadamente, a instância política:-em outras palavras, em seus estudos sobre as principais criações da "razão grega", ele se atém conscientemente à mediação em relação às condições históricas gerais exercida pela cidade-estado.

A diferença do escopo teórico e suas conseqüências pode ser claramente compreendida através da consideração de um problema particular: a questão do significado da idéia (tão importante para a primeira filosofia grega) de que a geração do “cosmos"se faz por um processo de luta e separação de contrários qualitativos. Vernant vê nessa idéia a ressonância das importantes transformações sociais, que culminaram com o aparecimento da "pólis"': a substituição de uma personagem única, que domina toda a vida social (rei), por uma multiplicidade de personagens cujas funções se opõem e se limitam reciprocamente, de tal modo que o campo social aparece como um composto heterogêneo de elmentos heterogêneos $(21: 27-31)$. Por isso, todo o domínio do "pré-jurídico" (anterior ao movimento legislador que teve lugar nas "póleis" já constituídas) representa uma espécie de "agón", de luta ou combate codificado e sujeito a regras, em que grupos se defrontam; e é também por isso que a ação política em seus primórdios toma a forma de disputa (21:32). Entretanto, à aceitação dos valores da luta, da concorrência, da rivalidade, a " pólis"' acrescenta o sentimento de dependência para com uma só e mesma comunidade $(21: 31)$. É a partir desses dois quadros que os filósofos, ao procurar explicar a geração do universo, chegam à idéia de uma oposição de qualidades contrárias que não se destroem mutuamente, mas, pelo contrário, se equilibram (21:89 e

* Diz, textualmente: “Quer se trate de fatos religiosos - mitos, rituais, representaçð̃es figuradas - de filosofia, de ciência, de arte, de instituiçð̃es sociais, de fatos técnicos ou econômicos, nós os consideramos sempre enquanto obras criadas pelos homens, como expressão de uma atividade mental organizada"' (26:3).

**É o que acontece, por exemplo, em algumas passagens de 21 , onde o ponto de partida da crise do século VII é apresentado como sendo de ordem econômica, e no artigo "La lutte des classes" (25), descrito na "Introdução" "de 27 como se inscrevendo" nos quadros de um debate interior ao marxismo" (27:17-20). 
$23: 184)$. Na cidade e na natureza, existem a oposição e uma ordem que a domina: a oposição é criadora enquanto se mantém nos limites dessa ordem.

Para Mondolfo, entretanto, nenhuma experiência restrita ao interior da "pólis" poderia dar conta de uma idéia tão complexa como a de "oposição criadora". Na raiz de todo "agón' que ocorre no âmbito da "pólis" existe uma injúria unilateral, vinda de uma das partes; ora, no processo cósmico universal a injúria entre os opostos é recíproca (10:63). Há apenas uma experiência interior à "pólis" em que parece haver realmente injúria recíproca: a das guerras-civis; de qualquer modo, a conseqüência dessa luta de todos contra todos não é a criação, mas sim o esfacelamento do "cosmos" social (10:67). Por isso, Mondolfo levanta a hipótese de que, na formação dos conceitos usados por Anaximandro e Heráclito intervieram elementos históricos diversos e que transbordam largamente da experiência interior à "pólis": a experiência de guerras externas, a experiência da colonização, a tradição mítica (que dava um amplo lugar às lutas entre os deuses), etc. (10:71-72). A fonte do conceito de "oposição criadora" deve ser buscada, pois em uma experiência histórica ampla. Isso torna a investigação da derivação da reflexão sobre a natureza de uma reflexão anterior sobre o mundo humano bem mais complexa e difícil, como vimos, mas também muito mais satisfatória.

$\mathrm{O}$ absoluto silêncio de Vernant a respeito de Mondolfo - cuja obra é, entretanto, bastante anterior à sua - permitenos supor que ele não chegou a conhecêlo. O que é, sem dúvida, de se lamentar, uma vez que o pensamento de ambos, apesar dos pontos de partida diversos, parece seguir caminhos próximos, com pontos de contato evidentes. Podemos especular sobre o que poderia ter sido um diálogo entre eles. E não deixa de ser um tributo à profunda dedicação de Mondolfo a problemas árduos e fundamentais da história da filosofia imaginar que, se ele tivesse escrito em outras línguas que não o italiano e o espanhol, ou se tivesse retornado à Europa, uma vez cessados os problemas que o trouxeram para a América Latina, os chamados estudos gregos teriam tomado um rumo menos erudito e mais vivo bem antes do momento em que disso se encarregaram Vernant e o grupo de que faz parte.

PRATES E SILVA, R.C.B. - Rodolfo Mondolfo and the beginning of greek philosophy. Trans/Form/Ação, São Paulo, 4:51-60, 1981.

ABSTRACT: The present article intends to call the attention to the role played by Rodolfo Mondolfo, with his theory of the early greek philosophy's dependence in relation with an earlier reflexion about man and social life, in the "turning" that restored the beginning of phylosophy into history.

KEY-WORDS: Philosophy; history of philosophy; philosophy and myth; philosophy and culture; philosophy and social life; philosophy and politics.

REFERÊNCIAS BIBLIOGRÁFICAS

1. HEIDEL, W. A. - $\pi \varepsilon \varrho \iota \gamma \mu \tau \varepsilon \omega \varsigma$. Proceedings of the Academy of Arts and Sciences, Boston, 1910 .

2. MONDOLFO, Rodolfo - Caratteri e sviluppi della filosofia presocrática. Sophia, Roma, giugl./set., 1934.
3 nos Aires, Losada, 1952.

4 de la cultura. Buenos Aires, Imán, 1942.

5 ria de cultura. In:
Historia de la filosofia, histoProblemas 
de cultura y de educacion. Buenos Aires, Hachette, 1937. p. 145-58. cetto centrale de la filosofia presocrática. Atene e Roma, Roma, apr./giug., 1935.

7 ze, La Nuova Italia, 1950.

8

cosmologia d'Instruzione Clasica, Roma, giug., 1935.

9 presocratica. Roma, La Nuova Italia, 1934.

10 origenes de la filosofia. In: - El pensap. 9-103.

Problema umano e problema cosmico nella formazione della filosofia greca. Bolonha, Academia de Ciências, 1934. Memória.

12 educación. Buenos Aires, Hachette, 1937. tigación en la história de la t Aires, Eudeba, 1960. Bolonha, Cappelli, 1936.

Problemi del pensiero antico.

Rapporti tra la speculazione religiosa e la filosofia nella Grecia antica. Firenze, La Nuova Italia, 1932.

Responsabilitá e sanzione nel piú antico pensiero greco. Roma, Civiltà Moderna, 1932.

Sugestiones de la técnica en los naturalistas presocraticos. Archeion, Santa $\mathrm{Fe}, 1941$.
18 PRO, Diego. - Rodolfo Mondolfo. Buenos Aires, Losada, 1968.

19 SCHUHL, Pierre Máxime - Essai sur la formation de la pensée grecque. Paris, Presses Universitaires de France. 1949.

20 THOMSON, George - The first philophers. Londres, Laurence and Wishart, 1955.

21 VERNANT, Jean Pierre - As origens do pensamento grego. São Paulo, Difusão Européia do Livro, 1972.

Do mito à razão. In: Mito e pensamento entre os gregos. São Paulo, Difusão Européia do Livro, 1973. p. 293-319.

Estrutura geométrica e noções políticas na cosmologia de Anaximandro. In:

Mito e pensamento entre os gregos. São Paulo, Difusão Européia do Livro, 1973. p. 168-86.

Geometria e astronomia esférica na primeira cosmologia grega. In:

Mito e pensamento entre os gregos. São Paulo, Difusão Européia do Livro, 1973. p. 156-67.

La lutte des classes. In:

Mythe et société en Grèce ancienne. Paris, François Maspero, 1974. p. 17-29.

Mito e pensamento entre os gregos. São Paulo, Difusão Européia do Livro, 1973.

27 ancienne. Paris, François Maspero, 1974.

Mito e tragédia na Giécia antiga. São Paulo, Duas Cidades, 1977.

29 Sobre a atualidade do helenismo. Discurso, São Paulo, n. ${ }^{\circ} 8$, maio, 1978. Entrevista. 